Discussion

Papers

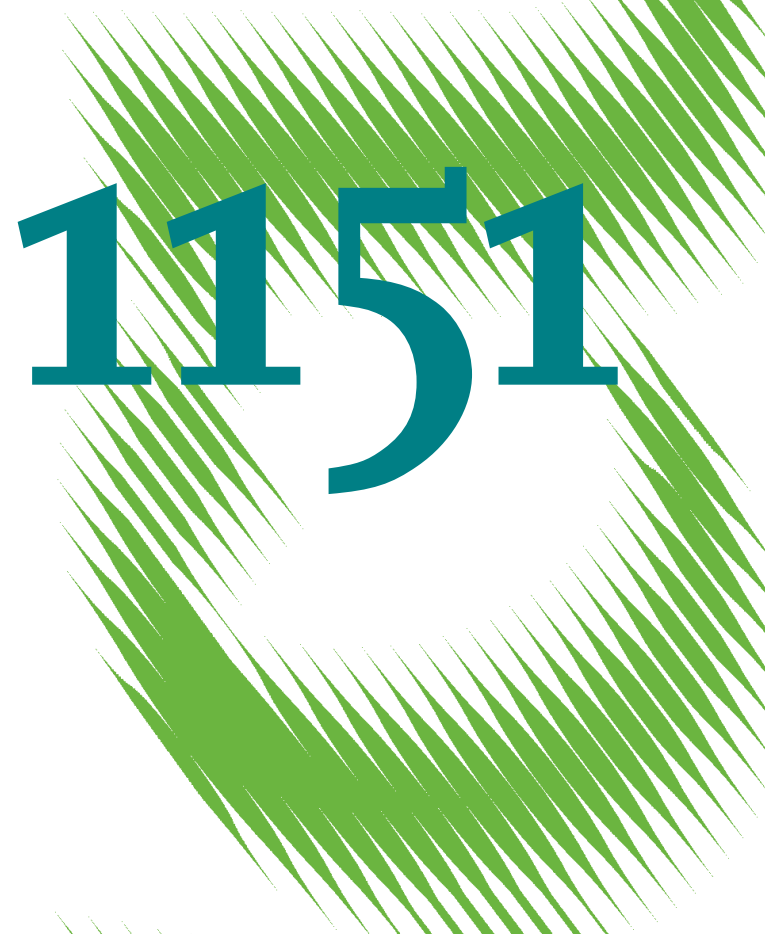

The Chinese Impact on GDP Growth and Inflation in the Industrial Countries 
Opinions expressed in this paper are those of the author(s) and do not necessarily reflect views of the institute.

IMPRESSUM

(C) DIW Berlin, 2011

DIW Berlin

German Institute for Economic Research

Mohrenstr. 58

10117 Berlin

Tel. $+49(30) 89789-0$

Fax +49 (30) $89789-200$

http://www.diw.de

ISSN print edition $1433-0210$

ISSN electronic edition 1619-4535

Papers can be downloaded free of charge from the DIW Berlin website:

http://www.diw.de/discussionpapers

Discussion Papers of DIW Berlin are indexed in RePEc and SSRN:

http://ideas.repec.org/s/diw/diwwpp.html

http://www.ssrn.com/link/DIW-Berlin-German-Inst-Econ-Res.html 


\title{
The Chinese impact on GDP growth and inflation in the
}

\section{industrial countries}

\section{Christian Dreger and Yanqun Zhang ${ }^{1}$}

\begin{abstract}
The integration of China into the global economy is one of the most spectacular events in economic history. This paper investigates to what extent this process affects output growth and inflation in the advanced countries. A GVAR model is specified to explore interdependencies between business cycles in China and industrial countries, including the US, the euro area and Japan. For robustness, the results are compared to those obtained from leading structural models, such as NiGEM and OEF. Evidence is based on the responses to a Chinese demand shock arising from the recent fiscal stimulus program. The results show that the impact on output growth in the advanced economies can be quite substantial, especially for the Asian region. The expansionary effects in the US and the euro area responses are lower, as trade linkages are less intensive. The multipliers are also reduced by a sizeable effect on inflation, as Chinese firms participate in international production chains.
\end{abstract}

JEL: E32, F15, C51

Keywords: GVAR, Chinese economy, shock transmission

\footnotetext{
${ }^{1}$ Dreger: German Institute for Economic Research (DIW Berlin), European University Viadrina Frankfurt Oder, Germany, email: cdreger@diw.de, Zhang: Chinese Academy of Social Sciences (CASS), Beijing, China, email: yqzhang@cass.org.cn. Yanqun Zhang thanks the fund of Chinese Academy of Social Sciences for the key research projects.
} 



\section{$1 \quad$ Introduction}

The integration of China into the world economy has been one of the most spectacular events in economic history. In only three decades, China transformed from a closed and agricultural country to the second largest economy in the world, with a share of about 10 percent of global GDP in PPPs. The industrialized world has benefitted from the development due to manufactured and intermediate products at lower costs and new markets. For example, China absorbs more than 10 percent of the exports from the advanced countries, after 5.5 percent at the turn of the century. Trade intensity measures suggest that China is already well integrated into the world economy (Bussière and Schnatz, 2006). At the same time, concerns have increased as the manufacturing and labour intensive industries have gone under high competition in the advanced economies, further intensified by exchange rate pressures. These reservations have gained importance as unemployment has risen in many countries during the last recession. Although the global imbalances have declined since then, they are still striking and pick up again (Feldstein, 2011).

The rising weight of China in the world economy may affect the macroeconomic development in the industrial countries. For example, the integration can lead to a higher divergence of business cycles between emerging and the advanced countries, i.e. stronger decoupling. In that case, the global economy would become more resistant against shocks arising from the advanced economies. However, these effects should not be exaggerated. As the global financial crisis have shown, emerging markets remain highly vulnerable to the evolution of the advanced economies. After initial decoupling, global economic activity became temporarily highly synchronized in the second half of 2008 . This does not constitute evidence against the decoupling hypothesis per se: the magni- 
tude of the shock has been unprecedented by historical standards and may hide more positive secular trends. Despite this argument, the economic recovery has been characterized by a revival of the decoupling hypothesis, i.e. huge growth divergencies across countries, with a strong increase in output in China and some other emerging markets and modest growth in major industrial states. The policy implications from a coupling or decoupling of national business cycles are manifold. A trend towards decoupling can reduce the risk of protectionism. The integration of China could have also impacts on the group of industrial economies. For example, it could allow the US and the euro area to synchronize their cycles less closely. In that case, a slowdown in the US would be less harmful for the euro area.

The degree of comovement of economic activity across countries has been explored by numerous studies. However, the literature did not arrive at robust conclusions and the evidence is limited to the period before the financial crisis. Hence, the issue is still an open area of research. Most papers have looked on business cycle dynamics across advanced countries and particular regions. Stock and Watson (2005) concluded from their analysis that output comovement for the G7 countries has fallen over the 1984-2002 period relative to $1960-83$, most likely due to the absence of common shocks. According to Artis and Zhang (1997) and Artis, Krolzig and Toro (2004) a common component affects the cyclical evolution in the euro area countries. Sato and Zhang (2006) and Shin and Sohn (2006) reported evidence for business cycle convergence in East Asia, probably driven by trade integration.

Only a few papers have extended the scope of the analysis to explore patterns between industrial and emerging markets. Following Kose, Otrok and Prasad (2008), business cycles have converged among the groups of advanced and emerging market economies, 
respectively. Since the relevance of the global factor has declined, there is cyclical convergence within each group, but divergence between them. Globalization did not change the degree of the pattern of international synchronization because the joint contribution of the global and group-specific factors has been rather stable over time. While common components play a larger role for business cycles in the group of advanced economies, country specific factors are more important for the emerging markets (Kose, Otrok and Whiteman, 2003). One rationale for this finding might be that many emerging countries have reached only intermediate levels of financial integration, i.e. they are not able to improve risk sharing opportunities (Kose, Prasad and Terrones, 2007). The high savings rate in China of almost 50 percent may be interpreted as an indication of poorly developed financial markets.

The Kose, Otrok and Prasad (2008) finding of a low correlation of business cycles between emerging and industrial countries is at odds with Frankel and Rose (1998). Especially China has substantial trade linkages to major developed states. According to Fidrmuc, Korhonen and Bátorová (2008) there is little evidence for comovement between industrial countries and China at business cycle frequencies, as many correlations are negative. However, the ties are positive in the very short run, in line with strong relationships between suppliers in China and final producers in the developed countries. Hence, the result might reflect vertical trade specialization, especially for intermediate products. In a different vein, Pula and Peltonen (2009) emphasized that trade statistics overestimate the level of integration that actually takes place, because of multiple counting of products in fragmented production processes.

To explore the interdependencies, most authors looked on static and dynamic bivariate correlations of the cyclical components of output and the ability of global or regional 
factors to explain national business cycles. This paper takes a different route and specifies a global VAR (GVAR) model to investigate the impact of a Chinese demand shock on GDP growth and inflation in industrial countries, including the US, the euro area and Japan. The recent fiscal stimulus package is considered as an example. For robustness, the results are compared to those obtained by leading structural macroeconometric models, such as NiGEM and OEF. The results demonstrate that the impact on output growth in the advanced economies is quite substantial, especially for the Asian region. The expansionary effects in the US and the euro area responses are lower, as trade linkages are less intensive. The multipliers are also reduced by a sizeable effect on inflation, as Chinese firms participate in international production chains.

The rest of the paper is structured as follows. The next section (Section 2) presents the Chinese fiscal stimulus program as an example for a huge demand shock. Afterwards the econometric tools are dicscussed. They include global VAR (Section 3) and structural macroeconometric models (Section 4). Section 5 holds the results. Finally, Section 6 concludes.

\section{$2 \quad$ China's fiscal stimulus package}

Despite clear signals of a recession in industrial countries, China experienced high output growth in the first period of the financial crisis. However, after the collapse of the Lehman bank, GDP growth decreased markedly as major export markets deteriorated. Thousands of firms closed down especially in the export-oriented coastal areas and millions of workers lost their jobs from one day to the other. A deceleration of growth is a matter of concern for several reasons. According to many observers, an annual rate of 8 
percent of output growth is the minimum level to generate enough jobs for the smooth integration of labour migrants into the workforce and to avoid social unrest that can otherwise destabilize the country. Furthermore, high growth is a way of papering over weaknesses of the economy and provides one of the best instruments for solving structural problems (Prasad, 2007).

It is against this backround that the Chinese government decided to launch a fiscal stimulus package of 3.1 and 2.7 percentage points of GDP in 2009 and 2010, respectively. The package includes higher investment in infrastructure in rural areas and large scaled projects like railroads, roads and airports and to a minor extent measures to improve the livelihood of the people, such as a stronger social safety net, the construction of low rent housing, better quality of public healthcare and education. See Naughton (2009) for a breakdown of individual expenditures.

The package may lead to a higher path of private consumption as precautionary savings are reduced. The decrease of public social transfers is often seen as a factor behind the decline of the consumption to GDP ratio in the pre-crisis period. Private households had to save more to finance future expenditures on health, old age consumption and education (Baldacci, Callegari, Coady, Ding, Kumar, Tommasino and Woo, 2010). The package does not reverse the export- and investment led growth strategy (Xu, 2010). Strategic export oriented industries are further supported in the next five year plan. But a more balanced path of the expansion is planned, putting higher weight on domestic demand and the production of non-tradables and services. Therefore, China could become less vulnerable against global shocks.

The fiscal stimulus appears to be successful at first sight. China recovered from the crisis quickly and the economy continued to rise at high rates. According to the input out- 
put analysis presented by He, Zhang and Zhang (2009) the fiscal multiplier is slightly about 0.8 in the short run and increases to 1.1 in the medium run. The package can potentially generate up to 20 million new jobs in the non-farming sectors. In addition, the simulation evidence provided by Cova, Pisani and Rebucci (2010) points to strong positive effects. About 2.5 percentage points of the recent growth experience might be attributed to the stimulus. Taken these results for granted, lower growth rates should be expected for the period ahead, since the measures will not be prolonged indefinitely. Despite the impact on the Chinese economy, other countries might be affected. Triggered by higher GDP growth imports will also accelerate, implying better export opportunities for the rest of the world.

\section{$3 \quad$ Global VAR models}

Global VAR (GVAR) models provide a convenient framework to explore international transmission mechanisms. The model is based on VARs for $N+1$ countries, see Pesaran, Schuermann and Weiner (2004) and Garratt, Lee, Pesaran and Shin (2006). The country specific models are linked as foreign variables are allowed to enter the equations. Due to the low number of degrees of freedom, the latter are measured as aggregates. In the $\operatorname{VARX}(1,1)$ specification

$$
x_{i t}=a_{i 0}+a_{i 1} t+\Phi_{i} x_{i, t-1}+\Lambda_{i 0} x_{i t}^{*}+\Lambda_{i 1} x_{i, t-1}^{*}+u_{i t}
$$

$i$ is the country index and $t$ denotes time. Furthermore $x_{i t}$ is a vector of $k_{i}$ domestic variables, and $x^{*}{ }_{i t}$ a vector with $k_{i}^{*}$ country specific foreign variables, i.e. constructed by a weighting scheme relevant for the particular country. The system might be extended by common factors representing global variables such as oil prices. In addition, $\Phi_{i}$ is a $k_{i} x k_{i}$ 
matrix of coefficients for the lagged domestic variables, and $\Lambda_{i 0}$ and $\Lambda_{i 1}$ are $k_{i} x k_{i}^{*}$ matrices associated with the coefficients of the foreign variables in contemporaneous and lagged form. Deterministic components can include intercepts and linear time trends. Finally, $u_{i t}$ is a vector of $k_{i}$ serially uncorrelated idiosyncratic shocks with zero mean and nonsingular covariance matrix. If autocorrelation patterns exist, further lags are added to the VARX. Shocks are allowed to be contemporaneously correlated, both across the equations for a specific country and across countries. International spillovers can arise due to a contemporaneous impact of the foreign on the domestic variables, through a dependence on global variables and through the contemporaneous correlation structure of the shocks.

The foreign variables are country-specific. To construct the series, the weights might be chosen in line with bilateral trade flows (Dees, Di Mauro, Pesaran and Smith, 2009). As an alternative, Vansteenkiste (2007) suggested weights based on the geographical distance between the regions, and Hiebert and Vansteenkiste (2007) used weights from input-output tables across sectors. The set of foreign specific variables for the ith country is

(2) $\quad x_{i, t}^{*}=\sum_{j=1}^{N} w_{i, j} x_{j, t}$

where the weights $w_{i, j}$ add to unity and $w_{i, i}$ is equal to zero. The weights could also be time-varying as long as they are predetermined. This could be particularly important in the case of rapidly expanding emerging economies with fast changing trade relations to the rest of the world. Before the full system can be specified, each VARX is consistently estimated on separate grounds. The foreign variables are treated as weakly exo- 
geneous with respect to the parameters of interest. In the context of cointegrated models, the weak exogeneity assumption implies no long-run feedback from the domestic to the foreign variables, i.e. the error correction term is not significant for the latter series (Juselius, 2005). This does not rule out lagged short-run feedback between the two sets of variables. The weak exogeneity restriction can be tested in the context of the individual models.

Once the VARXs have been estimated, all variables need to be solved in a simultaneous manner. By grouping the domestic and foreign variables, the country specific VARs can be stated as

$$
\mathrm{A}_{i} z_{i, t}=a_{i, 0}+a_{i, 1} t+\mathrm{B}_{i} z_{i, t-1}+u_{i, t}
$$

where

$$
\mathrm{A}_{i}=\left(\mathrm{I}_{k_{i}},-\Lambda_{i, 0}\right) \quad, \quad \mathrm{B}_{i}=\left(\Phi_{i}, \Lambda_{i, 1}\right) \quad, \quad Z_{i t}=\left(\begin{array}{c}
x_{i t} \\
x_{i t}^{*}
\end{array}\right) .
$$

The $k x 1$ global vector $x_{t}$

$$
x_{t}=\left(x_{0 t}{ }^{\prime}, x_{1 t}{ }^{\prime}, \ldots, x_{N t}{ }^{\prime}\right)^{\prime}, \quad k=\sum_{i=0}^{N} k_{i}
$$

holds the variables gathered from all countries in the system. The model can be rewritten in terms of the $x$-vector by using the identity

(4) $\quad \mathrm{z}_{i, t}=\mathrm{W}_{i} x_{t}$

where $\mathrm{W}_{i}$ is the $\left(k_{i}+k_{i}^{*}\right) \mathrm{x} k$ link matrix obtained from the country specific weights. The GVAR arises from the VARXs 
$\mathrm{A}_{i} \mathrm{~W}_{i} x_{t}=a_{i, 0}+a_{i, 1} t+\mathrm{B}_{i} \mathrm{~W}_{i} x_{t-1}+u_{i, t}$

by stacking the individual models

(5) $\quad \mathrm{G} x_{t}=a_{0}+a_{1} t+\mathrm{H} x_{t-1}+u_{t}$

$\mathrm{G}=\left(\begin{array}{c}\mathrm{A}_{0} \mathrm{~W}_{0} \\ \mathrm{~A}_{1} \mathrm{~W}_{1} \\ \vdots \\ \mathrm{A}_{N} \mathrm{~W}_{N}\end{array}\right), \quad \mathrm{H}=\left(\begin{array}{c}\mathrm{B}_{0} \mathrm{~W}_{0} \\ \mathrm{~B}_{1} \mathrm{~W}_{1} \\ \vdots \\ \mathrm{B}_{N} \mathrm{~W}_{N}\end{array}\right) \quad, \quad a_{0}=\left(\begin{array}{c}a_{00} \\ a_{01} \\ \vdots \\ a_{0 N}\end{array}\right), \quad a_{1}=\left(\begin{array}{c}a_{10} \\ a_{11} \\ \vdots \\ a_{1 N}\end{array}\right) \quad, \quad u_{t}=\left(\begin{array}{c}u_{0 t} \\ u_{1 t} \\ \vdots \\ u_{N t}\end{array}\right)$

Provided that G is nonsingular, the model (5) can be solved for $x_{t}$. The dynamics of the system are explored by impulse response analysis and variance decompositions. These tools ars considered in a generalized form, i.e. they are invariant to the ordering of variables and countries (Pesaran and Shin, 1998). Even if a suitable ordering of the variables in a VARX might be taken from economic theory, it is not clear how to order countries in the GVAR.

\section{Structural macroeconometric models}

Besides the GVAR, evidence is obtained on the grounds of two leading structural global macroeconometric models, namely the NiGEM (National Institute for Economic and Social Research, 2011) and the OEF model (Oxford Economic Forecasting, 2011). Although the models differ in detail, they share some basic properties. Both are designed for forecasting and policy simulation. Because of the forecasting issue, the equations are fitted to historical data. Individual country models are interlinked via several channels, like trade, commodity prices, asset holdings and associated income flows, exchange and 
interest rates. Forward looking agents are assumed especially in financial markets, but this depends on the particular specification.

The general structure is similar across countries, more or less. Potential GDP results from a Cobb Douglas or CES production function with labour augmenting technical progress. Technical progress is taken as exogeneous for the advanced economies, but for catching up economies, it might also depend on FDI. The production function constitutes the theoretical background for the specification of the factor demand equations for employment and capital. Firms bargain with workers over wages, and choose the extent of labour conditional to output and real wages. In equilibrium, real wages move in line with productivity. A rise in unemployment has a dampening effect on real wages, implying that they fall relative to their trend. Inflation is inherently a monetary phenomenon in the long run. Monetary policy sets the short term interest rate to achieve its target. In particular, interest rates move up if inflation is above the desired level and/or output is above potential. Actual GDP is equal to the sum of the demand aggregates. Private consumption depends on real disposable income, real financial wealth, real interest rates and inflation. Investment of firms is affected by the capacity utilization and Tobins $q$, i.e. investment rates are affected by their opportunity costs, after taking taxes and allowances into account. Exports are a function of world demand and the real exchange rate, where a world trade matrix ensures the fulfillment of adding-up constraints across countries. Imports are driven by real domestic demand and measures of competitiveness, such as relative unit labour costs or relative prices. Disequilibria between supply and demand are temporary and are represented by the output gap, i.e. the difference between actual and potential GDP, expressed as a percentage of the latter. The output gap is relevant for price adjustment, jointly with unit labour costs and import prices. 
Government spending and revenues depend on the state of the business cycle. For policy analysis, tax rates are treated as exogenous.

Due to the nonstationarity of most variables, the equations are usually specified in error correction format with suitable dynamics around the long run. The long run is either specified on theoretical grounds or estimated in advance. Both model alternatives are implemented as simultaneous equation systems. To exclude spillovers arising from huge errors in individual relationships, estimation is done equation by equation. An instrumental variable approach is used to control for endogeneous right hand side regressors. Interdependencies within a country and across countries are taken into account after estimation is done. Once the regression parameters are determined, the whole system is solved by simulation methods.

\section{$5 \quad$ Impact of a Chinese shock}

The GVAR model comprises equations for real GDP and CPI inflation. To capture international spillovers arising through financial markets, real equity prices, real exchange rates, nominal short and long term interest rates are also embedded on a country-bycountry basis. In each equation, the domestic variable is explained by its own lags, lags of the other variables of the system and lags of the foreign variables. The latter enter as an aggregate, with weights reflecting the relevance of the individual countries as trading partner for the domestic economy. Provided that the series are nonstationary, the equations are specified for the differenced variables, with error correction terms for the level variables included. All lag parameters are chosen in line with the Schwartz information criterion. The data are taken from the usual sources, such as the International Financial 
Statistics from the IMF and Datastream. Quarterly series are seasonal adjusted, and the observation period is from 1979Q1 to 2009Q4. The fiscal stimulus (3.1 and 2.7 percent of GDP in the first and second year) is implemented by respective GDP shock. The expected effects are obtained from the generalized impulse response analysis. In the structural models, the difference to the baseline scenario, i.e. the development without any additional measures is considered. See Table 1 for the impacts on GDP growth and Table 2 for the inflation response.

-Tables 1 and 2 about here-

The Chinese GDP is expected to rise because of the shock. Due to the acceleration in demand, CPI inflation is also affected. Actual output exceeds its potential, thereby causing additional inflation pressure. The size of the latter effect is estimated rather impreciely, with results ranging from slightly below one percentage point in the GVAR and OEF to almost three percentage points in the NiGEM specification ${ }^{2}$. The impact on inflation increases over time, indicating some degree of price stickiness. Overall, these estimates imply that a substantial part of the current inflation experience in China is attributed to domestic forces.

Regarding the international transmission of the shock, business cycle spillovers can be substantial, at least according to the GVAR and NiGEM environment. In contrast, they can be neglected in the OEF model. However, these results might be downward biased due to the low integration of China in the initial years of the sample period. According

\footnotetext{
${ }^{2}$ The GVAR results have been derived with the toolbox provided by Smith and Galesi (2011), version 1.1 .
} 
to the GVAR and NiGEM specification, the GDP response is relatively high in Asia. Output growth in Japan rises up to one percentage point, reflecting higher export opportuinities of Japanese firms. See also Figure 1 for the GVAR impulse responses for GDP growth and CPI inflation. Therefore, China could trigger economic growth in the region $^{3}$. Furthermore, the GVAR reveals a remarkable acceleration of GDP growth in the US and the euro area, especially in the second year. However this effect is not robust. The reactions will decrease in the NiGEM model, with a negative multiplier in the US.

-Figure 1 about here-

The latter reaction can be partially linked to differences in the inflation response. While the rise in inflation is only minor in the US and the euro area in the GVAR, the reaction is more pronounced in the NiGEM specification. Private consumption will decline, as a reduction in the purchasing power of households is implied. Global inflation increases because of higher prices of products imported from China. This size of this effect depends on the extent to which Chinese products can be substituted. The lower the respective elasticities, the higher the impact on inflation.

\section{Conclusion}

The integration of China into the global economy is one of the most spectacular events in economic history. In three decades, China transformed from an agricultural country

\footnotetext{
${ }^{3}$ The impact on other countries such as the ASEAN states is also quite high. Results are not shown in the tables, but are available from the authors upon request.
} 
to the second largest economy in the world, with a share of 10 percent of global GDP (PPP). This paper investigates to what extent this process affects output growth and inflation in the advanced countries. A GVAR model is specified to explore interdependencies between business cycles in China and industrial countries, including the US, the euro area and Japan. For robustness, the results are compared to those obtained from leading structural models, such as NiGEM and OEF. Evidence is based on the responses to a Chinese demand shock arising from the recent fiscal stimulus program. The results reveal that the impact on output growth in the advanced economies can be quite substantial, especially for the Asian region. The expansionary effects in the US and the euro area responses are lower, as trade linkages are less intensive. The multipliers will be also reduced by a sizeable effect on inflation, as Chinese firms participate in international production chains. 


\section{References}

Artis M, Krolzig H-M, Toro J (2004): The European business cycle, Oxford Economic Papers 56, 1-44.

Artis M, Zhang W (1997): International business cycles and the ERM. Is there a European business cycle?, International Journal of Finance and Economics 2, 1-16.

Baldacci E, Callegari G, Coady D, Ding D, Kumar MS, Tommasino P, Woo J (2010): Public expenditures on social programs and household consumption in China, IMF Working Paper 10/69.

Baxter M, Kouparitsas MA (2004): Determinants of business cycle comovement: A robust analysis. Journal of Monetary Economics 52, 113-57.

Bussière M, Schnatz B (2006): Evaluating China's integration in world trade with a gravity model benchmark, ECB Working Paper 693.

Cova P, Pisani M, Rebucci A (2010): Macroeconomic effects of China's fiscal stimulus, Inter-American Development Bank, IDB Working Paper 211.

Dees S, Di Mauro F, Pesaran MH, Smith V (2007): Exploring the international linkages of the euro area: A global VAR analysis, Journal of Applied Econometrics 22, 1-38.

Eichengreen B, Tong H (2005): Is China's FDI coming at the expense of other countries? NBER Working Paper 11335.

Feldstein MS (2011): The role of currency realignments in eliminating the US and China current account imbalances, NBER Working Paper 16674.

Fidrmuc J, Korhonen I, Bátorová I (2008): China in the world economy. Dynamic correlation analysis of business cycles, BOFIT Discussion Papers 7/08. 
Frankel JA, Rose, AK (1998): The endogeneity of the optimum currency area criteria, Economic Journal 108, 1009-25.

Garratt T, Lee K, Pesaran MH, Shin Y (2006): Global and national macroeconometric modelling: A long run structural approach, Oxford University Press, Oxford.

He D, Zhang Z, Zhang W (2009): How large will be the effect of China's fiscal-stimulus package on output and employment?, Pacific Economic Review 14, 730-744.

Hiebert P, Vansteenkiste I (2007): International trade, technlogy shocks and sillovers in the labour market. A GVAR analysis for the US manufacturing sector, ECB Working Paper 731.

Kose MA, Otrok C, Prasad ES (2008): Global business cycles: Convergence or decoupling? NBER Working Papers 14292.

Kose MA, Otrok C, Whiteman CH (2003): International business cycles. World, region and country-specific factors, American Economic Review 93, 1216-1239.

Kose, MA, Prasad ES, Terrones M (2003): How does globalization affect the synchronization of business cycles?, American Economic Review 93, Papers and Proceedings, $57-62$.

Naughton B (2009): Understanding the Chinese stimulus package, China Leadership Monitor 28.

National Institute for Economic and Social Research (2011): The NiGEM model, http:// www.niesr.ac.uk/pdf/nigem2.pdf.

Oxford Economic Forecasting (2011): The Oxford global economic model, Oxford Economics, Oxford. 
Pesaran MH, Schuermann T, Weiner SM (2004): Modeling regional interdependencies using a global error- correcting macroeconometric model, Journal of Business and Economic Statistics 22, 129-162.

Pesaran MH, Shin Y 1998: Generalized impulse response analysis in linear multivariate models, Economics Letters 58, 17-29.

Prasad E (2009): Is the Chinese growth miracle built to last?, China Economic Review 20, 103-123.

Pula G, Peltonen TA (2009): Has emerging Asia decoupled? An analysis of production and trade linkages using the Asian international input-output table. ECB Working Paper 993.

Sato K, Zhang Z (2006): Real output co-movements in East Asia: Any evidence for a monetary union? World Economy 29, 1671-1689.

Shin K, Sohn C-H (2006): Trade and financial integration in East Asia: Effects on comovements. World Economy 29, 1649-1669.

Smith LV, Galesi A (2011): GVAR toolbox 1.1, www.cfap.jbs.cam.ac.uk/research/ gvartoolbox

Stock JH, Watson MW (2005): Understanding changes in international business cycle dynamics, Journal of the European Economic Association 3, 968-1006.

Xu Y (2010): China's export led growth strategy: An international comparison, China \& World Economy 18, 18-33. 
Table 1: Responses of real GDP to Chinese demand shock

\begin{tabular}{|l|c|c|c|}
\hline & GVAR & NiGEM & OEF \\
\hline China & $3.4 \mid 3.7$ & $3.0 \mid 2.7$ & $3.1 \mid 2.9$ \\
\hline Japan & $0.6 \mid 0.7$ & $0.9 \mid 0.4$ & $0.0 \mid 0.0$ \\
\hline US & $0.4 \mid 0.7$ & $0.2 \mid-0.3$ & $0.0 \mid 0.0$ \\
\hline Euro area & $0.3 \mid 0.5$ & $0.3 \mid 0.2$ & $0.0 \mid 0.0$ \\
\hline
\end{tabular}

Note: Responses to the fiscal stimulus program in China. Left (right) entry: Cumulated response after the first (second) year. Differences expressed as percentage points from the baseline.

Table 2: Responses of inflation to Chinese demand shock

\begin{tabular}{|l|c|c|c|}
\hline & GVAR & NiGEM & OEF \\
\hline China & $0.5 \mid 0.8$ & $1.3 \mid 2.7$ & $0.2 \mid 0.8$ \\
\hline Japan & $0.3 \mid 0.5$ & $0.1 \mid 0.4$ & $0.0 \mid 0.0$ \\
\hline US & $0.0 \mid 0.2$ & $0.2 \mid 0.6$ & $0.0 \mid 0.0$ \\
\hline Euro area & $0.0 \mid 0.1$ & $0.2 \mid 0.5$ & $0.0 \mid 0.0$ \\
\hline
\end{tabular}

Note: Responses to the fiscal stimulus program in China. Left (right) entry: Cumulated response after the first (second) year. Differences expressed as percentage points from the baseline. 
Figure 1: GVAR generalized impulse responses

GDP growth

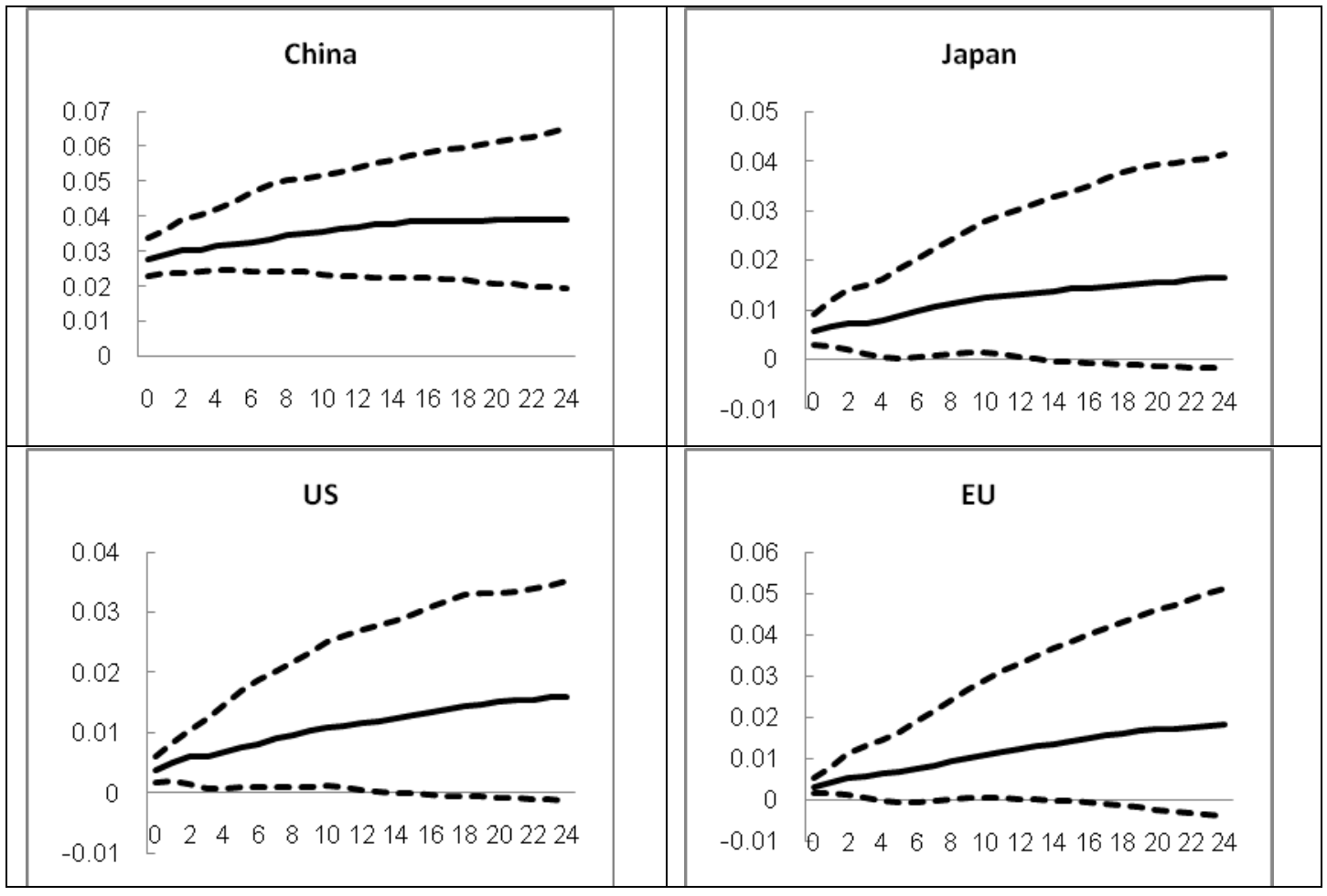

CPI inflation

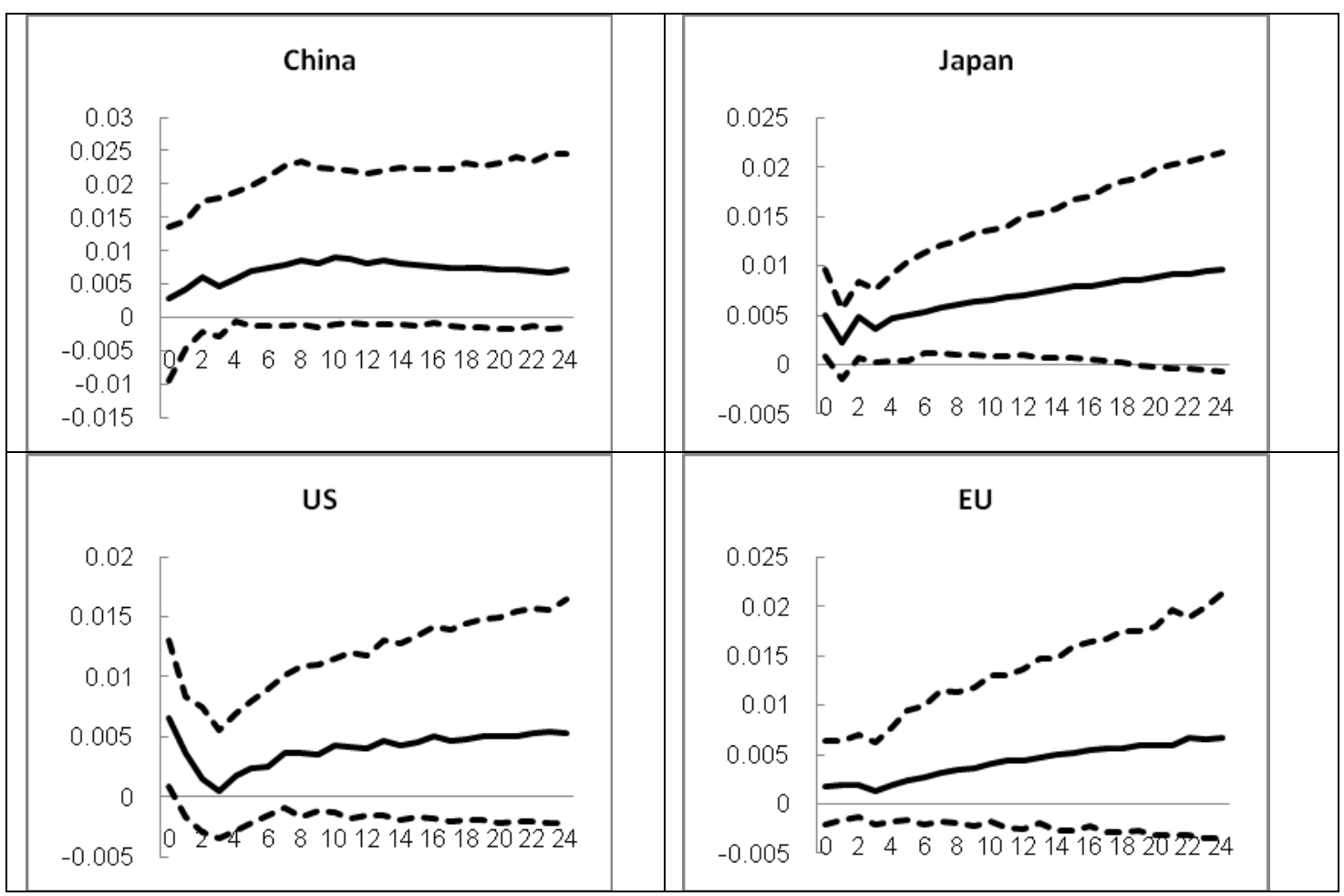

Note: Dotted lines denote 90 percent confidence bands. 